\title{
Functional dissection of the paired segmentation gene in Drosophila embryos
}

\author{
David Morrissey, David Askew, Lakshmi Raj, and Michael Weir \\ Department of Biology, Wesleyan University, Middletown, Connecticut 06459 USA
}

\begin{abstract}
An ectopic expression assay in Drosophila embryos was used to investigate the roles of pair-rule segmentation genes in the spatial regulation of the segment-polarity gene, engrailed (en). It is hypothesized that the regions of overlap in expression of two genes, paired (prd) and even-skipped (eve), define the odd-numbered en expression stripes. Consistent with this combinatorial model, ectopic expression of prd caused these en stripes to be expanded posteriorly. Surprisingly, however, ectopic expression of a prd gene with a deletion of the conserved paired box resulted in loss of these odd-numbered en stripes. This dominant negative effect is a phenocopy of en expression in prd embryos and suggests that the paired box is necessary for normal prd function. A similar deletion of odd-numbered en stripes was also observed after ectopic expression of a chimeric fushi tarazu (ftz) gene containing a substituted prd gene homeo box; in addition, in these embryos, the even-numbered en stripes were expanded anteriorly, as observed when the unaltered ftz gene is ectopically expressed. These effects suggest that the chimeric protein may have DNA or protein targets of both the normal Ftz and Prd proteins.
\end{abstract}

[Key Words: Segmentation genes; ectopic expression; homeo box; paired box]

Received May 15, 1991; revised version accepted June 24, 1991.

Precise and orderly spatial regulation of segmentation genes is critical for coding different developmental pathways in the Drosophila embryo. The zygotic segmentation genes are organized in a regulatory cascade (gap genes $\rightarrow$ pair-rule genes $\rightarrow$ segment-polarity genes), reflecting the progressive increase in refinement of their spatial patterns of RNA and protein expression (Akam 1987; Ingham 1988). Hence, within the cascade, the gap genes, which are expressed in broad patches, are upstream of the pair-rule genes, which are expressed in striped patterns with two-segment periodicity; these, in turn, are upstream of the segment-polarity genes, which are expressed in stripes with one-segment periodicity. We have focused on the transition in this cascade between the pair-rule and segment-polarity genes, using as a model problem, the regulation of the segment-polarity gene engrailed (en) by the pair-rule genes fushi tarazu (ftz), even-skipped (eve), and paired (prd).

Two general models have been suggested for the regulation of segment-polarity genes such as en. Gergen et al. (1986) were first to suggest that the segment-polarity genes may be regulated by combinatorial mechanisms; that is, specific combinations of pair-rule gene products are required to define the expression stripes of the segment-polarity genes. Combinatorial regulation is supported as a possible mechanism, both by genetic studies indicating that mutations in many pair-rule genes alter the RNA and protein expression patterns of segment- polarity genes and by the observation that pair-rule genes are expressed in complex arrays of overlapping patterns that in principle could define the segment-polarity gene expression domains (see below). A contrasting model, proposed by Lawrence et al. (1987), emphasizes the importance of the expression boundaries of the pair-rule genes $(f t z$ and $e v e)$ in the specification of the en stripes. They observed that in germ-band-elongated embryos, the anterior borders of $l a c Z$ expression stripes driven by $f t z$ or eve promoters coincide cell by cell with the anterior borders of $e n$ stripes in even- and odd-numbered parasegments, respectively, suggesting that $f t z$ and $e v e$ may define the anterior edges of the respective en stripes.

Elements of both these models have been incorporated into more recent discussions of en (DiNardo and O'Farrell 1987; Ingham et al. 1988, Weir et al. 1988). Figure 1 illustrates our current view of en regulation. The essence of this "boundary-combinatorial" model is that the en stripes are defined by the overlapping expression of several pair-rule genes. The model proposes that expression of en RNA by nuclei in odd-numbered stripes (within odd-numbered parasegments) requires the presence of two positive regulators, the products of eve and $p r d$ (Eve and Prd proteins). Expression of $e n$ in even-numbered stripes requires the presence of the positive regulator $\mathrm{Ftz}$, and the presence or absence of a positive or negative regulator that is yet to be identified. Consistent with this, loss-of-function mutations in any of these pos- 
A.

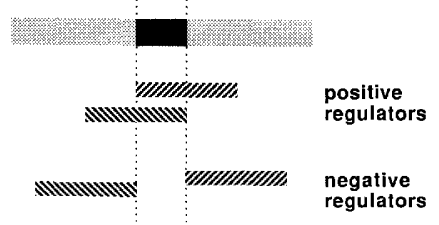

B.

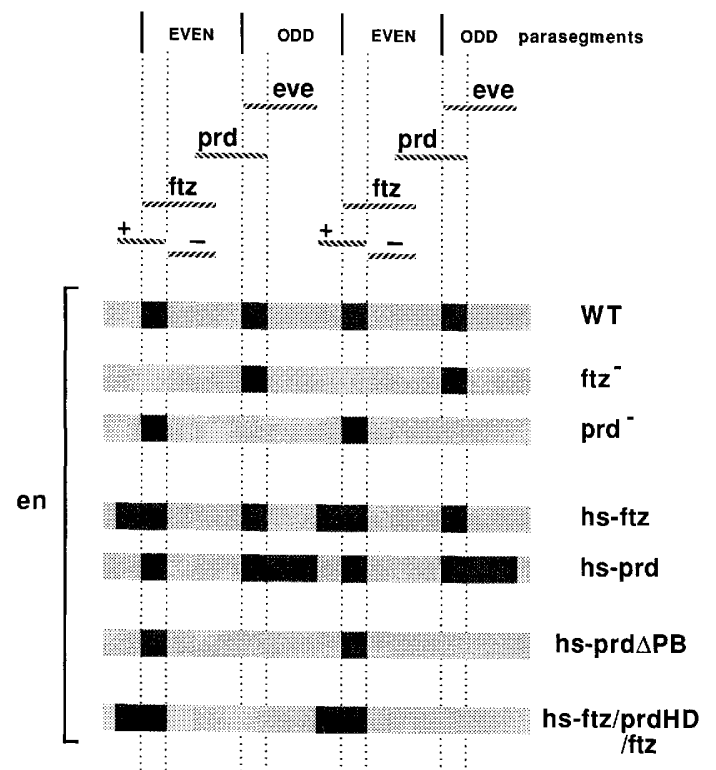

Figure 1. The regulation of en. $(A)$ Boundary specification. 11lustrated is the general hypothesis that the boundaries of expression of a gene can be specified by either positive or negative regulators with the same expression boundaries (Weir et al. 1988; Carroll 1990). (B) A boundary-combinatorial model for en regulation. This regulatory scheme, based on previous models (DiNardo and O'Farrell 1987; Ingham et al. 1988, Weir et al. 1988), proposes that the anterior and posterior borders of the odd-numbered en stripes are defined by eve and prd, respectively. The anterior borders of the even-numbered en stripes are defined by $f t z$; whether the posterior borders of these stripes are defined by a positive or negative regulator is unknown. The relative expression domains of $e n$ and its regulators support the model (see text and Fig. 2). Also consistent with the model, loss-of-function mutations in $f t z$ or prd result in the absence of even- or odd-numbered en stripes, respectively (Howard and Ingham 1986; DiNardo and O'Farrell 1987; Ingham et al. 1988). In addition to lacking odd-numbered en stripes, eve mutants also lack even-numbered stripes, probably because the $f t z$ expression domains are shifted in eve embryos (Harding et al. 1986; Macdonald et al. 1986; Frasch et al. 1988). Because the pair-rule regulators define specific en boundaries, these boundaries should be respecified when the pair-rule gene is expressed ectopically. As predicted, ectopic $f t z$ causes the anterior border of even-numbered en stripes to be respecified, as illustrated (IshHorowicz et al. 1989|. Ectopic prd causes the posterior border of odd-numbered stripes to be shifted posteriorly (this study). Also illustrated are the effects of ectopic expression of two constructs: a prd gene with a deletion of the paired box (hs-prd $\triangle P B)$ and a ftz gene with a prd gene homeo domain (hs-ftz/prdHD/ $f t z)$. itive regulators results in the absence of the appropriate en stripes as illustrated (Fig. 1). We describe the model as a boundary-combinatorial model because the pair-rule regulators effectively define the boundaries of en expression (Fig. 1A). Thus, the postulated spatial relationship between the expression of $e n$ and its regulators implies that the anterior edges of the odd- and even-numbered en stripes are specified by $e v e$ and $f t z$, respectively, and the posterior edges of odd-numbered stripes are defined by prd (Fig. 1B). This is supported by expression studies as described above (also see Results).

In this study we investigated the role of the prd gene in the regulation of $e n$. As with $f t z$ and $e v e$, the prd gene has a homeo box that is thought to encode DNA-binding activity in the protein product (Laughon and Scott 1984; McGinnis et al. 1984; Hoey and Levine 1988; for review, see Scott et al. 1989). In vitro studies (Treisman et al. 1989) suggest that the binding specificity of the Prd homeo domain may depend in part on the identity of the ninth residue of the homeo domain recognition helix (the second helix of the helix-turn-helix). In addition to the homeo domain, the prd gene also encodes an evolutionarily conserved domain of 128 amino acids, the paired-box domain, which is also thought to have a DNA-binding activity different from that of the Prd homeo domain (Bopp et al. 1986; Burri et al. 1989; Treisman et al. 1991). The functional significance of these putative dual binding activities within the same Prd protein is presently unknown: For example, does the combinatorial regulation of $e n$ rely on both of these binding activities? As a first step in dissecting the in vivo function of the Prd protein, we expressed the prd gene ectopically using a heat-inducible $h s p 70$ promoter. This resulted in characteristic changes in embryonic expression of $e n$ that were consistent with the boundary-combinatorial model (Fig. 1). Because these changes were distinct from those observed after ectopic expression of $f t z$, we decided to use this ectopic expression assay to test two altered versions of prd and ftz: a prd gene with a deletion of the paired box, and a $f t z$ gene with a substituted prd homeo box. The product of the paired-box deletion gene appeared to have a dominant negative effect on the function of the resident endogenous prd gene, providing evidence that the paired box is important for the functioning of the Drosophila prd gene. The ftz-prd chimera also appeared to have a similar dominant negative effect on prd function and also had aspects of $f t z$ function. These observations suggest that regions both inside and outside of the homeo domain may be important in the specification of targeting of these homeo domain proteins.

\section{Results}

Comparison of expression domains of en, $\mathrm{ftz}$, and prd

As a prelude to the ectopic expression studies, we wished to verify that the normal spatial expression of the prd gene is consistent with that predicted by the boundarycombinatorial model for en regulation. According to the model, the posterior borders of odd-numbered en stripes 
should coincide with the posterior borders of prd stripes (Fig. 1B). Hence, as illustrated in Figure 2a, superimposition of the expression domains of prd and $f t z$ should reveal interbands the same width as the en interbands in odd-numbered parasegments. To test this prediction, we hybridized embryos with $p r d$ and $f t z$ probes simultaneously. Examination of embryos at gastrulation, the time when the array of en expression stripes is first detected (DiNardo et al. 1985; Weir and Kornberg 1985), revealed interbands lacking $p r d$ and $f t z$ expression that were two to three cells wide, the same width as the corresponding en interbands (cf. square brackets in Fig. 2ac; see also Kilchherr et al. 1986). This result is consistent with the hypothesis that prd gene-expression boundaries
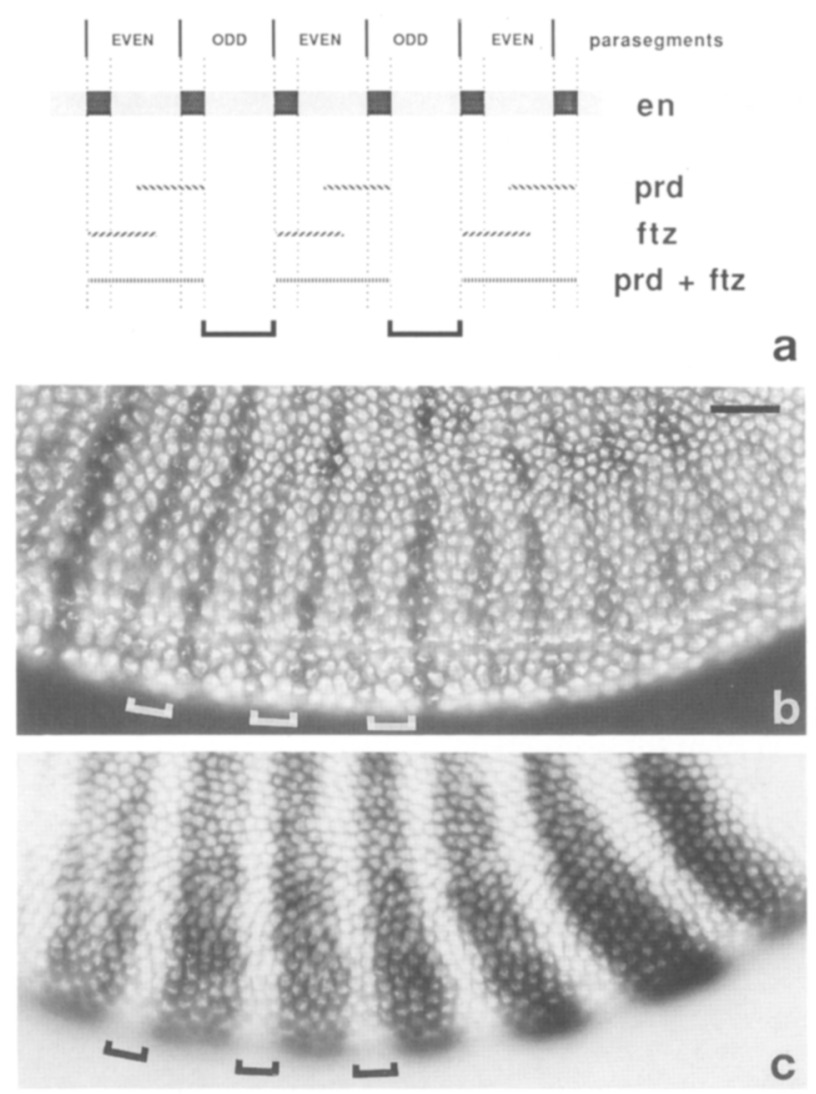

Figure 2. The definition of $e n$ interbands in odd parasegments. (a) Summary diagram illustrating the correspondence of expression domains of en, prd, and $f t z .(b, c)$ In both images, regions of darker staining correspond to regions of gene expression (RNA or protein). (b) Immunostaining of En protein (see Karr et al. 1989) in an early gastrula illustrating expression stripes (dark) one to two cells wide separated by interbands two to three cells wide. (c) Whole-mount in situ hybridization with prd and $f t z$ probes simultaneously reveals interbands the same width as the en interbands in odd parasegments (two to three cells wide; brackets in $a, b$, and $c$ ). This is consistent with there being a coincidence of the posterior borders of $p r d$ and odd-numbered en stripes (Fig. 1). $b$ and $c$ are both lateral views of similarly aged embryos shortly after gastrulation, visualized using simultaneous bright-field and DAPI optics. Bar, $25 \mu \mathrm{m}$. coincide with and specify the posterior borders of oddnumbered en stripes. Supporting this conclusion, direct comparison of En and Prd protein distributions revealed a coincidence of the posterior borders of odd-numbered En stripes and Prd stripes (T. Gutjahr and M. Noll, pers. comm.).

\section{Ectopic expression of prd}

To further investigate the putative role of the prd gene in the regulation of en, we constructed germ-line transformant lines containing an extra copy of the prd gene under the control of an hsp 70 promoter (Fig. 3A). These transformants were tested for ectopic expression of prd by heat-treating embryos in nuclear cycle 14 [170-200 min after egg deposition (AED) at $25^{\circ} \mathrm{C}$ ] for $5 \mathrm{~min}$ at $37^{\circ} \mathrm{C}$. In situ hybridization with a prd probe revealed high levels of RNA expression throughout these embryos at all stages in cycle 14. Significant levels of ectopic prd RNA were observed at 5 and 20 min after the end of heat shock (see Fig. 6c, below) and somewhat lower levels were detected after $40 \mathrm{~min}$.

To test whether the introduced prd gene had biological activity, we examined the cuticle patterns of larvae that were heat treated during embryogenesis in the latter part of cycle $14\left(170-200 \mathrm{~min} \mathrm{AED}\right.$ at $\left.25^{\circ} \mathrm{C}\right)$, the time when the pair-rule genes are thought to regulate spatially the segment-polarity genes. We observed a phenotypic series of cuticle patterns (Fig. 4a-c) that were altered compared with wild type (Fig. 4d), indicating that the introduced prd gene has biological activity. Patterns ranged from complete or almost complete deletion of all denticle belts (Fig. 4a) to complete (Fig. 4b) or partial (Fig. 4c) deletion of every other denticle belt. Similar patterns were observed in embryos that were heat treated earlier in cycle 14 (not shown). Comparison of the weaker hsprd phenotypes (Fig. 4c) with weaker prd $^{-}$phenotypes (Nüsslein-Volhard and Wieschaus 1980) suggested that the $h s-p r d$ and $p r d^{-}$phenotypes are qualitatively different: $h s-p r d$ embryos with less pronounced deletions have partial deletions of even-numbered abdominal denticle belts, whereas weaker $\mathrm{rrd}^{-}$phenotypes have partial pairwise fusions of even-numbered denticle belts with their anterior neighboring denticle belt. As summarized in Figure 4e, this suggests that in hs-prd embryos, the centers of deletions lie over the even-numbered denticle belts; whereas in $p r d^{-}$embryos, the centers are over the naked cuticle anterior of these denticle belts. Interestingly, analogous partially overlapping deletions were observed in heat shock $\mathrm{ftz}$ and $\mathrm{ftz}^{-}$embryos (Struhl 1985).

To assay more directly the regulatory effect of the ectopic prd, we examined the patterns of en RNA in heattreated hs-prd embryos. Unlike wild-type embryos, which have evenly spaced stripes of approximately equal width (Fig. 5a), the spacing and widths of the $e$ stripes in $h s-p r d$ embryos were reproducibly altered. In germband-elongating embryos, the odd-numbered stripes were broader, and the interbands behind these stripes were narrower than in wild type (Fig. 5b-d). This indicates that the posterior borders of the odd-numbered 

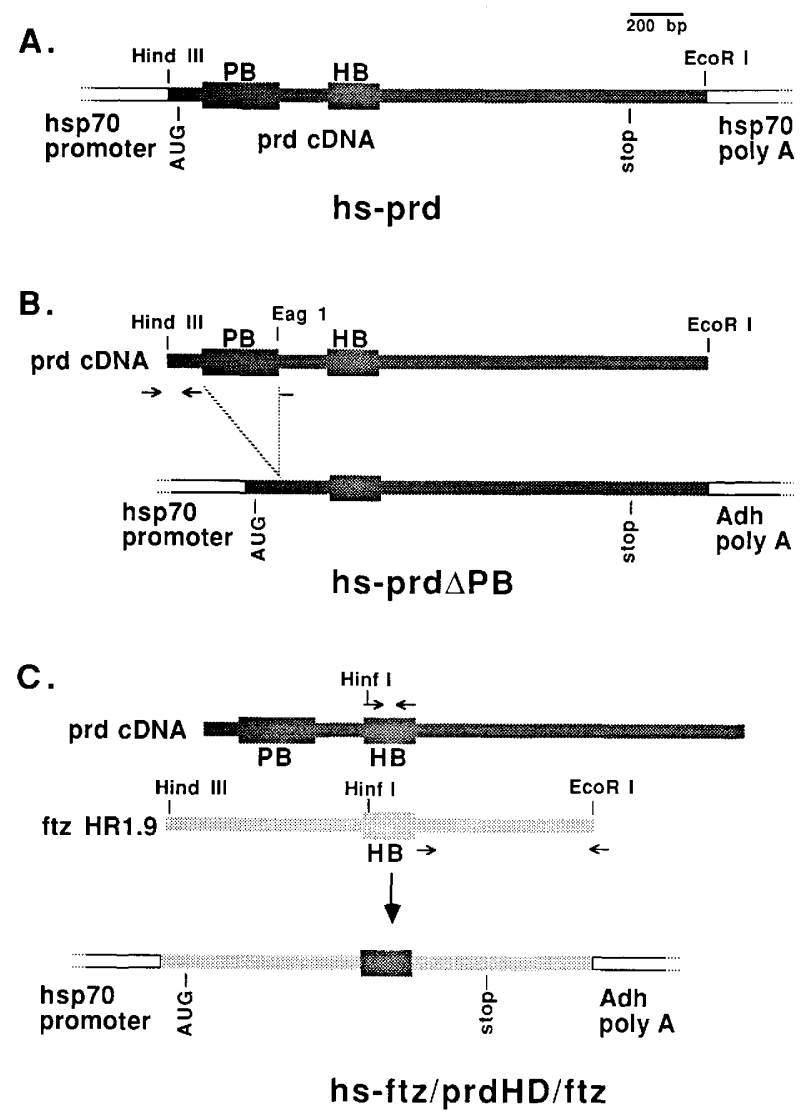

Figure 3. Maps of heat shock constructs. (A) The hs-prd construct. Illustrated is the hs-prd construct, which consists of a HindIII-EcoRI fragment of prd cDNA (c7340.6; Frigerio et al. 1986) cloned between $h s p 70$ promoter and polyadenylation sequences. The prd sequence includes only $32 \mathrm{bp}$ upstream of the AUG translation start codon and 308 bp downstream of the translation stop codon, which includes the prd cDNA polyadenylation signal (AATAAA) but does not include the prd gene polyadenylation site. $(B) h s-p r d \triangle P B$ is similar to $h s-p r d$ except that DNA encoding 125 of 128 amino acids of the paired-box domain has been deleted. (C) The hs-ftz/prdHD/ftz construct has an in-frame substitution encoding residues 3-61 of the Prd homeo domain substituting for the equivalent residues of Ftz. The $f t z$ sequence includes $\sim 90 \mathrm{bp}$ upstream of the translation start codon and $421 \mathrm{bp}$ downstream of the stop codon, which does not include the $f t z$ polyadenylation signal or site. Arrows in $B$ and $C$ illustrate PCR primers used for the constructions. The constructs in $B$ and $C$ include polyadenylation sequences from the $A d h$ gene instead of hsp70. (PB) Paired box; (HB) homeo box.

stripes are shifted posteriorly, as predicted by the boundary-combinatorial model (see Fig. 1B). In younger embryos just after gastrulation, low levels of extra en expression were detected throughout the interbands on the posterior side of the odd-numbered en stripes (not shown). The altered en patterns were observed at 40 or $60 \mathrm{~min}$ after heat shock but were not obvious at $20 \mathrm{~min}$ after the end of heat shock. The new patterns were not observed in some of the heat-treated $h s-p r d$ embryos, possibly because the period of heat shock was short (5$10 \mathrm{~min}$; Fig. 5). However, longer periods of heat shock were not used in our expression studies because they cause significant disruption of nuclear cycling in both wild-type and hs-prd embryos (M. Weir, unpubl.).

In the hs-prd embryos, the odd-numbered en stripes were often more intense than their even-numbered neighbors (Fig. 5b,c). This is in contrast to expression in wild-type embryos in which the even-numbered stripes develop earlier and are transiently more pronounced than their odd-numbered neighbors (DiNardo et al. 1985; Weir and Kornberg 1985). This result is consistent with observations that prd RNA stripes generally develop later than the corresponding eve stripes in normal development (L. Waldman and M. Weir, unpubl.). Hence, ectopic expression of prd before its normal expression would be expected to result in abnormally early en expression as observed.

Our observation that ectopic prd causes the posterior borders of odd-numbered en stripes to be shifted posteriorly parallels the effects of ectopic ftz (Struhl 1985), which causes the anterior borders of even-numbered en stripes to be shifted anteriorly (Ish-Horowicz et al. 1989) as predicted. In this case, the expression stripes of the endogenous $f t z$ gene are also expanded one to two cells anteriorly; therefore, it is not known whether the expanded en expression is caused by the heat-induced or expanded endogenous $f t z$ expression. Given that expression of endogenous $f t z$ is altered in heat-treated $h s-f t z$ embryos, we decided to examine endogenous prd expression in $h s-p r d$ embryos. Because the introduced prd gene lacked most of the untranslated leader sequence of the endogenous transcript, we were able to use a $140-\mathrm{bp}$ leader sequence probe to measure specifically the endogenous prd expression. At 5, 20, and $40 \mathrm{~min}$ after the end of heat shock, endogenous prd was expressed in striped patterns similar to those observed in wild-type embryos (cf. Fig. 6a with b). Hence, it is likely that the broadened en stripes observed in $h s-p r d$ embryos are a consequence of regulation by the heat-induced ectopic (Fig. 6c) rather than endogenous (Fig. 6b) prd expression.

According to the boundary-combinatorial model (see Fig. 1B), the broadened en stripes in heat-treated $h s-p r d$ embryos would be explained by a broadened region of overlap between prd and eve expression during specification of the en stripes. In normal development eve stripes gradually become narrower during cycle 14, reaching a width of about two cells at the time of gastrulation (Harding et al. 1986; Macdonald et al 1986). Our comparison of eve RNA expression in wild-type and hs-prd embryos at 20 and $40 \mathrm{~min}$ after heat shock revealed similar patterns of eve stripes (data not shown), indicating that ectopic prd does not affect the eve expression at this stage in development. This is consistent with the hypothesis that the expanded overlapping expression of eve and prd is responsible for the broadened en stripes. The combinatorial model also predicts that in the absence of $e v e$ function, broadened odd-numbered en stripes should not be observed. It has been shown previously that in $e v e^{-}$embryos during germ-band elonga- 


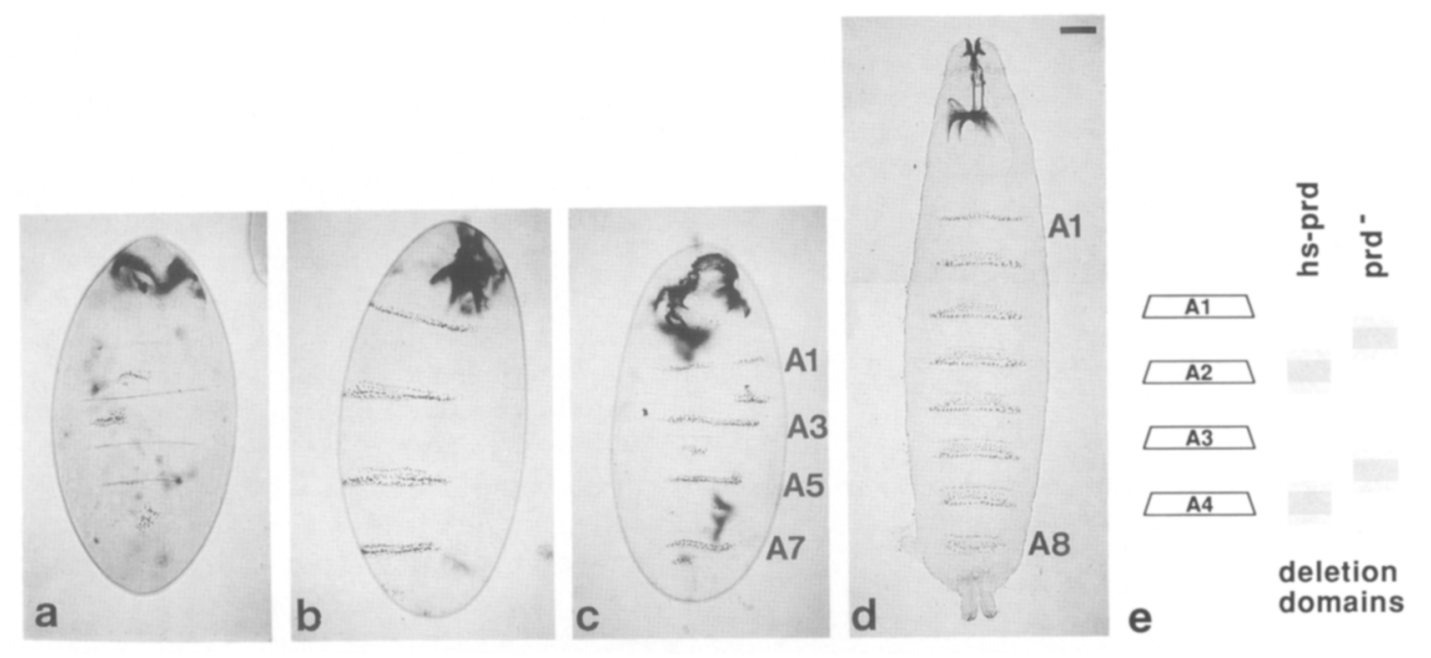

Figure 4. Cuticle patterns in $h s-p r d$ embryos. $(a-c)$ Phenotypic series showing altered cuticle patterns in heat-treated $h s-p r d$ embryos. (a) Strong phenotype: partial or complete deletion of all denticle belts. (b) Intermediate pair-rule phenotype: complete deletion of even-numbered abdominal denticle belts. $(c)$ Weak phenotype: partial deletion of even-numbered denticle bands. $(d)$ Cuticle pattern in wild-type embryo. Embryos were heat treated for $20 \mathrm{~min}(a, b)$ or $10 \mathrm{~min}(\mathrm{c})$ starting at 170-200 min AED. Embryos in $a$ and $b$ are from a homozygous infertile line; those in $c$ are from a homozygous fertile line; however, the same range of patterns was observed in both lines. (e) Summary diagram illustrating the partially overlapping deletion domains observed in $h s-p r d$ and $p r d^{-}$cuticle patterns. (Al-A4) Abdominal denticle belts. Weaker $h s-p r d$ or prd ${ }^{-}$phenotypes have deletions of only the centers of the deletion domains (darker shading). Hence, weak hs-prd embryos lack parts of even-numbered abdominal denticle belts $(c)$, whereas prd ${ }^{-}$embryos lack some naked cuticle between odd-numbered and their posterior neighboring denticle belts, resulting in partial fusions of these belts (Nüsslein-Volhard and Wieschaus 1980). Bar, $50 \mu \mathrm{m}$.

tion, there is a deletion of all en stripes except for limited expression in the head region (Harding et al. 1986; Macdonald et al. 1986). We observed the same en pattern in $h s-p r d$ embryos homozygous for $e v e^{1.27}$ (a small chromosomal deletion removing the eve genel fixed at 40 min after heat shock (not shown). This indicates that eve function is necessary for the broadened odd-numbered en stripes in hs-prd embryos. Taken together, these data support a combinatorial role for prd and eve in the regulation of $e$.

\section{Deletion of the paired box}

Because the ectopic expression of prd caused characteristic changes in the expression of $e n$, we decided to use this in vivo assay to test the ectopic function of altered versions of the prd gene. To test this approach, we constructed a prd gene lacking the conserved paired box, normally located upstream of the prd homeo box (hsprd $\triangle P B$; see Fig $3 \mathrm{~B}$ ). Heat treatment of hs-prd $\triangle P B$ embryos with two 5 -min pulses during cycle 14 resulted in an altered cuticle pattern, suggesting that the $h s-p r d \triangle P B$ gene has biological activity. In embryos with strong phenotypes, much of the naked cuticle between denticle belts was substituted with a reverse-polarity, mirrorsymmetric pattern of denticles (Fig. 7a), a phenotype similar to that observed in the segment-polarity mutant gooseberry (Fig. $7 \mathrm{~b}$; Nüsslein-Volhard and Wieschaus 1980). In $h s-p r d \triangle P B$ embryos with weaker phenotypes, there was less deletion of the naked cuticle between denticle belts and not all denticle belts had mirror-image patterns (not shown). These cuticle phenotypes were observed in two independent transformant lines.
Heat treatment of $h s-p r d \triangle P B$ embryos had an unexpected dominant negative effect on the expression of $e$. The odd-numbered en stripes were often partially or completely deleted (Fig. 7c); the even-numbered expression stripes were of normal strength and width. This deletion of odd-numbered $e n$ stripes is a phenocopy of $e n$ expression in prd $^{-}$embryos. However, the effect of $h s-$ prd $\triangle P B$ is not caused by an insertion mutation into the prd gene, which is on the second chromosome, as one of the two tested transformant lines has an insertion on the third chromosome. Consistent with this, expression of endogenous prd RNA was not detectably altered in hsprd $\triangle P B$ embryos (not shown). To explain the deletion of odd-numbered en stripes in $h s-p r d \triangle P B$ embryos, we suggest instead that the $\operatorname{Prd} \Delta \mathrm{PB}$ protein may poison the function of the endogenous Prd protein (see Discussion).

\section{Swapping homeo boxes}

To examine the relative contributions of regions inside and outside the homeo box to the functioning of $f t z$ and prd, we decided to use ectopic expression to test a chimeric $f t z$ gene with a prd homeo box. The chimera (hsftz/prdHD/ftz; see Fig. 3C) was introduced into flies by germ-line transformation. To verify that a chimeric gene had indeed been introduced, we performed in situ hybridizations with two probes, a ftz probe and a prd homeo box probe, and examined RNA levels at 5 min after the end of heat shock treatment. For both probes significant levels of uniform expression were observed, consistent with the ectopic expression of the chimeric gene (not shown). 


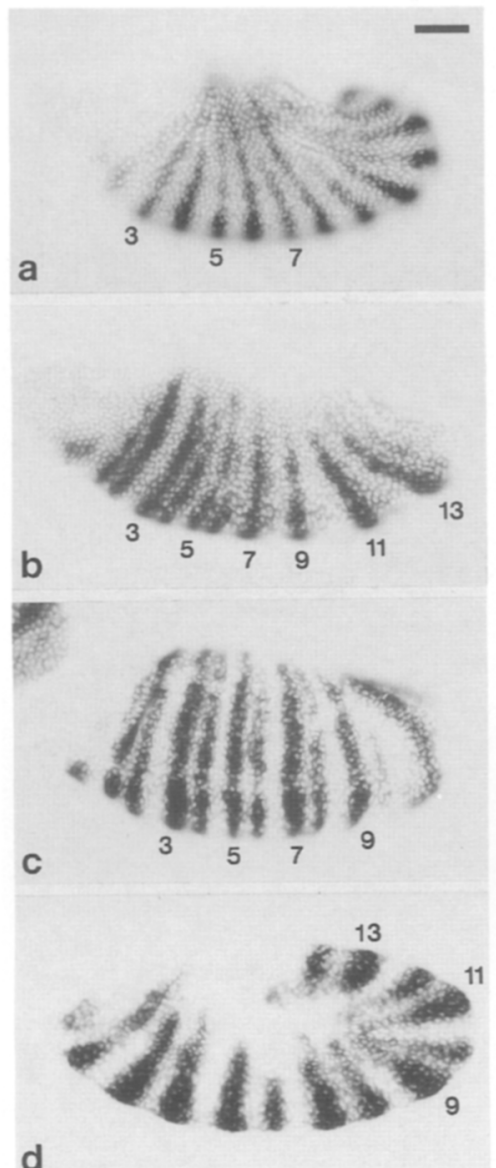

Figure 5. Expression of en RNA in wild-type and hs-prd embryos. (a) Wild-type en pattern shortly after the beginning of germ-band elongation: en is expressed in 14 stripes of equal width separated by interbands of equal width. $(b-d)$ Heattreated hs-prd embryos: en expression is altered compared to wild type. The odd-numbered stripes are broader than normal, and the interbands posterior of these stripes are narrower. In younger embryos early in germ-band elongation $(b, c)$, odd-numbered stripes are often more pronounced than their even-numbered neighbors (e.g., stripes 9, 11, 13) (see text). In older embryos further into germ-band elongation $(d)$, the broadening of odd-numbered en stripes is most pronounced toward the posterior (stripes 9, 11, 13). Embryos $b-d$ are homozygous for the $h s-p r d$ insertion. Embryos $b$ and $c$ were heat treated with two 5 -min pulses separated by $30 \mathrm{~min}$, and fixed $40 \mathrm{~min}$ after the end of the second pulse. Embryo $d$ was heat treated for $5 \mathrm{~min}$ and fixed 40 min later. Embryos were photographed with brightfield and DAPI epifluorescence simultaneously. $(a, b, d)$ Lateral views, ventral down; $\{c\rangle$ lateral-ventral oblique view. Bar, $50 \mu \mathrm{m}$.

A "pair-rule-like" cuticle phenotype was observed in hs-ftz/prdHD/ftz embryos that were heat treated in cycle 14 with two 5 -min pulses (Fig. 8a), suggesting that the chimeric gene has biological function. Embryos with a strong pair-rule phenotype had half the normal number of denticle belts, whereas embryos with weaker phenotypes had partial deletions of even-numbered abdominal denticle belts or partial pairwise fusions of even-numbered belts with their more posterior neighbors. These phenotypes suggest that the regions of cuticle deleted in these embryos included the even-numbered belts and the naked cuticle posterior of these belts (Fig. 8b). This phenotype differs from that of $h s-p r d$ in that although the same denticle belts were deleted, pairwise fusions were observed in $h s-f t z / p r d H D / f t z$ but not hs-prd embryos, suggesting that the regions of cuticle deleted lie slightly more posteriorly in $h s-f t z / p r d H D / f t z$ (Fig. 8b). However, the regions of cuticle deleted in $h s-f t z / p r d H D / f t z$ embryos appear to be the same as those deleted in $h s-f t z$ embryos (Fig. 8b; Struhl 1985), consistent with the possibility that the hs-ftz/prdHD/ftz chimera has aspects of function of ectopic $f t z$.

The expression of en was altered in two ways in heattreated $h s-f t z / p r d H D / f t z$ embryos. First, the odd-numbered en stripes were completely (Fig. 8c) or partially deleted (Fig. 8d), as observed in $h s-p r d \Delta \mathrm{PB}$ embryos. Hence, the Ftz/PrdHD/Ftz chimera, like the $\operatorname{Prd} \Delta \mathrm{PB}$ protein, appears to poison the normal specification of the odd-numbered en stripes. A second effect was observed. The even-numbered $e n$ stripes were expanded anteriorly (Fig. 8d,e), as was observed in hs-ftz embryos (see Fig.

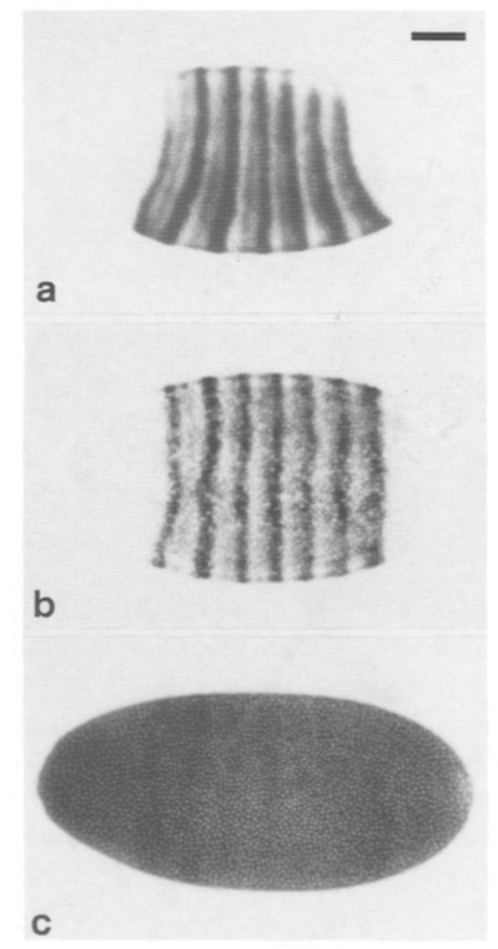

Figure 6. Expression of prd RNA in wild-type and hs-prd embryos. (a) Wild-type expression of prd RNA late in cycle 14. Lateral view, ventral down $(b)$. Expression of endogenous prd RNA in a homozygous, heat-treated hs-prd embryo. Only endogenous prd is detected because the DNA probe consisted of $140 \mathrm{bp}$ of leader sequence that was present in the endogenous prd RNA but absent from the ectopically expressed prd RNA. The pattern of endogenous prd appears normal. The embryo was heat treated with two 5 -min pulses separated by $30 \mathrm{~min}$ and fixed 20 min later (ventral view). (c) General expression of ectopic prd RNA at $20 \mathrm{~min}$ after the end of 5-min heat treatment (ventral view). Bar, $50 \mu \mathrm{m}$. 


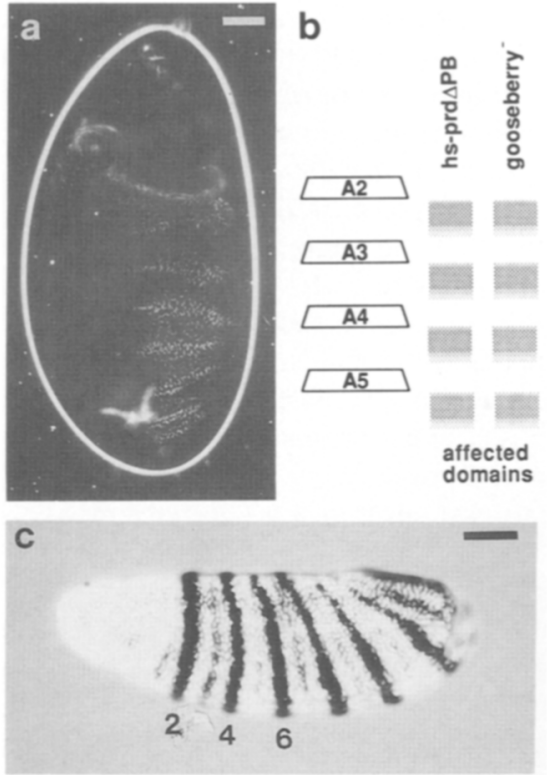

Figure 7. Analysis of hs-prd $\triangle P B$ embryos. (a) Cuticle patterns in hs-prd $\triangle P B$ embryos. Illustrated is an embryo in which much of the naked cuticle between each denticle belt was substituted with a mirror-image duplication of the denticle band. This phenotype is similar to that of the segment-polarity mutant goose berry. (b) Summary diagram showing the approximate domains that are substituted with mirror-image duplications of the remaining pattern in hs-prd $\triangle P B$ and gooseberry ${ }^{-}$embryos. $(c)$ Expression of en RNA in hs-prd $\triangle P B$ embryos. Ectopic expression of hs-prd $\triangle P B$ caused complete or partial deletion of odd numbered en stripes as shown. Even-numbered en stripes were of normal width and strength. Embryos shown here and in Figs. 8 and 9 were heat treated with two 5 -min pulses separated by 30 min and either fixed 40 min later for in situ analysis or incubated at $18^{\circ} \mathrm{C}$ for cuticle preparations. Bars, $50 \mu \mathrm{m}$.

1B), suggesting that the chimera may function like the unaltered Ftz protein, despite having a prd gene homeo domain.

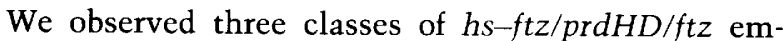
bryos with respect to deletions of odd-numbered stripes and expansions of even-numbered stripes: (1) deletions alone (Fig. 8c); (2) deletions and expansions (Fig. 8d); and (3) expansions alone (Fig. 8e). Within a given sample of heat-treated $h s-f t z / p r d H D / f t z$ embryos there was a tendency for the younger embryos to fall in the first class (deletions alone), intermediate ages in the second (deletion and expansion), and older embryos in the third (expansion alone). Because the older embryos did not have deletions, this suggests that the specification of oddnumbered stripes in these embryos may have passed beyond a period of sensitivity to ectopic expression of the chimera.

Given that the chimeric gene caused expansion of even-numbered en stripes, just as observed in hs-ftz embryos, it was of interest to determine whether the chimera was also able to "autoregulate" the endogenous $\mathrm{ftz}$ gene. As described earlier, ectopic $f t z$ causes the endogenous $f t z$ stripes to be expanded approximately one cell anteriorly (Ish-Horowicz et al. 1989). Examination of $f t z$ expression in hs-ftz/prdHD/ftz embryos shortly after gastrulation at $40 \mathrm{~min}$ after the end of heat treatment revealed that the $f t z$ expression stripes are also broader than in wild-type embryos. At this age, $f t z$ stripes in wild-type embryos are normally two to three cells wide (Fig. 9a); whereas in hs-ftz/prdHD/ftz embryos, the stripes are three to four cells wide, approximately the same width as the interbands (Fig. 9b). This result is consistent with the suggestion that ectopic chimera (hs$f t z / p r d H D / f t z)$, as with ectopic $f t z$, is capable of autoregulating the endogenous $f t z$ gene (Fig. 9c).

\section{Discussion}

Regulation of en requires boundary specification and combinatorial regulation

Ectopic expression of the prd gene caused the odd-numbered $e n$ stripes to be expanded posteriorly. This result supports a model for en regulation in which the prd gene acts in combination with another gene, probably eve, to specify the posterior and anterior boundaries, respec-
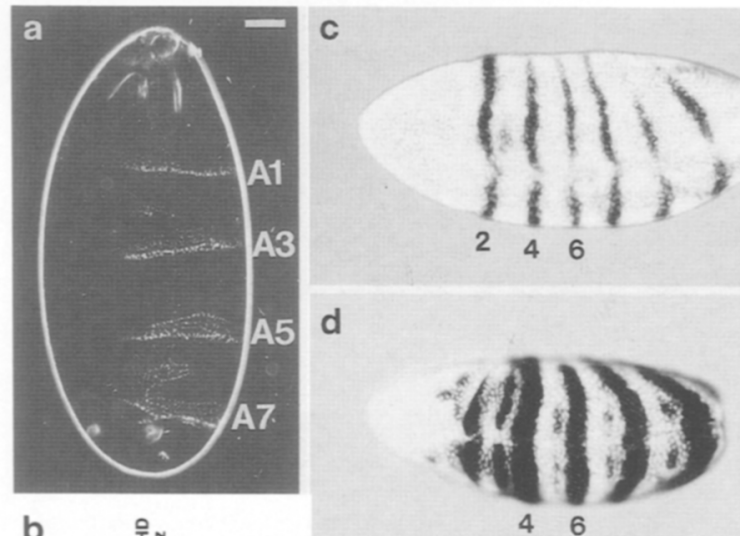

b

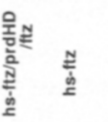

46
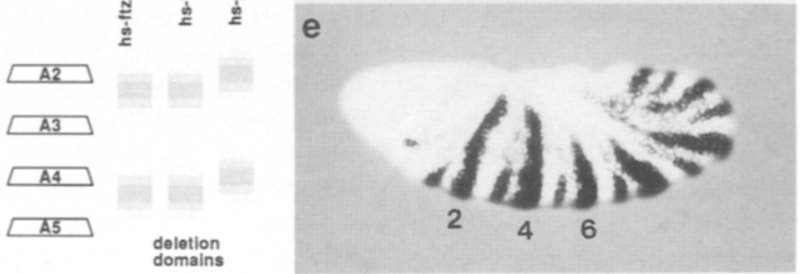

Figure 8. Analysis of $h s-f t z / p r d H D / f t z$ embryos. $(a)$ Cuticle patterns in heat-treated $h s-f t z / p r d H D / f t z$ embryos. A pair-rulelike phenotype was observed with half the normal number of abdominal denticle belts. We observed complete (e.g., A4) or partial (e.g., A2) deletions of even-numbered denticle bands and partial fusions of these bands with their posterior neighboring bands (e.g., A6). (b) Summary diagram of deleted domains. The same domains are deleted in $h s-f t z / p r d H D / f t z$ and $h s-f t z$ embryos. However, the deletion domains in hs-prd embryos are a little more anterior. $(c-e)$ en expression in $h s-f t z / p r d H D / f t z$ embryos. Ectopic expression of $h s-f t z / p r d H D / f t z$ had two effects: expansion of even-numbered en stripes and complete or partial deletion of odd-numbered en stripes. Three classes of embryos were observed with respect to these two effects: $(c)$ deletions only; $(d)$ deletions and expansions; and $(e)$ expansions only. Bars, $50 \mu \mathrm{m}$. 


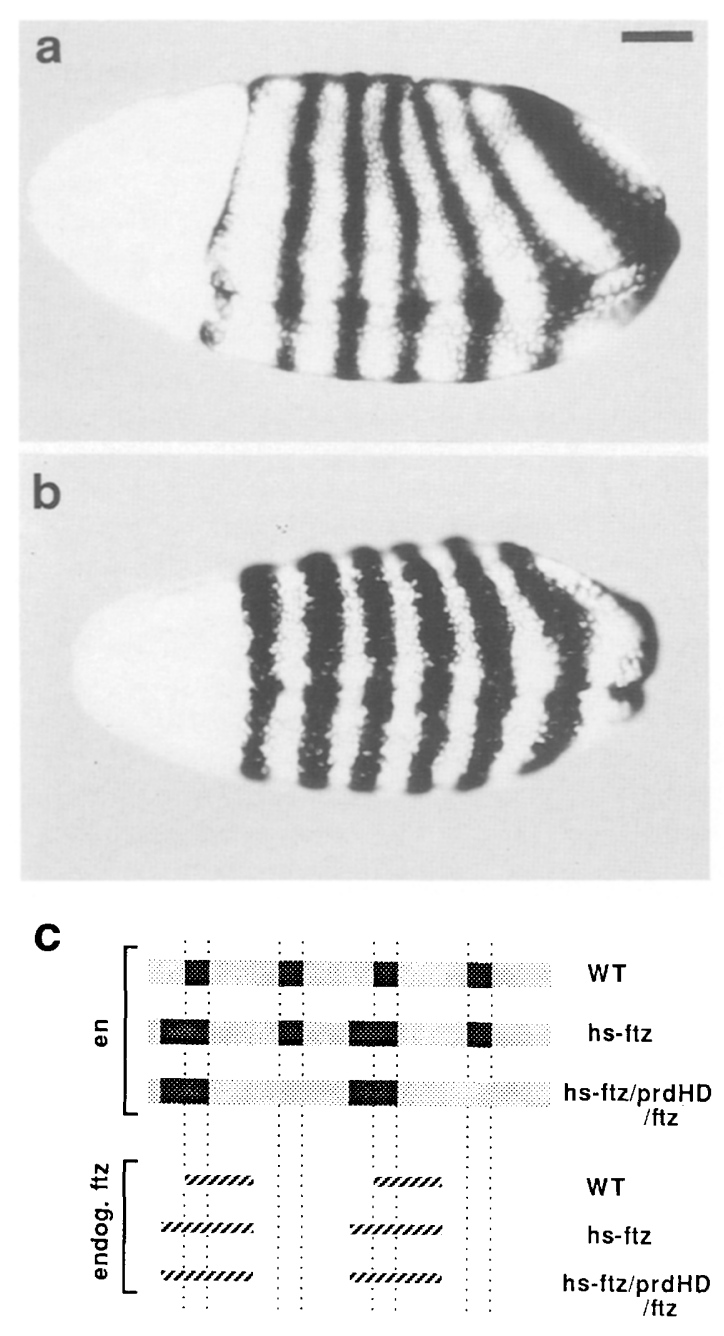

Figure 9. Autoregulation of $f t z$ by $h s-f t z / p r d H D / f t z . ~(a, b) f t z$ RNA in embryos shortly after the beginning of germ-band elongation. (a) Wild-type embryo. $f t z$ stripes are two to three cells wide. $(b) h s-f t z / p r d H D / f t z$ embryo. ftz stripes are three to four cells wide, separated by interbands of the same width. Although not demonstrated in this study, it is likely that the broadening of $f t z$ stripes is toward the anterior, as has been demonstrated in $h s-f t z$ embryos (Ish-Horowicz et al. 1989). (c) Summary diagram illustrating this interpretation of these expression patterns. Bar, $50 \mu \mathrm{m}$.

tively, of each odd-numbered en stripe (boundary-combinatorial model; see Fig. 1) According to this model, en is activated in those regions where both prd and eve are expressed. Hence, the ectopic expression of prd is expected to cause the regions of overlapping expression of prd and eve to be expanded (to encompass the eve stripes); hence, the regions of en expression are also expanded (see Fig. 1). The result supports the importance of both combinatorial regulation and boundary specification in the regulation of $e n$.

\section{Deletion of the paired box alters prd function}

Given that the observed changes in en expression in hs- prd embryos are as would be predicted for prd function at ectopic sites, this result provides an in vivo assay system to dissect which regions of the Prd protein are necessary for prd function. In addition to the homeo domain, the Prd protein contains another evolutionarily conserved motif, the paired-box domain, which, as it is conserved, is also expected to have some functional importance. Indeed, a point mutation in the homologous paired box of the mouse pax-1 gene (the undulated mutation) results in characteristic disruption of the mouse vertebral column (Balling et al. 1988). Furthermore, recent in vitro DNA-binding studies suggest that the paired-box domain of Drosophila Prd may have a DNA-binding activity that is distinct from that of the Prd homeo domain (Treisman et al. 1991).

To test in vivo the importance of the paired box in the Drosophila prd gene, we constructed a prd gene with an in-frame deletion of 125 of 128 amino acids of the pairedbox domain. Ectopic expression of this deletion construct $(h s-p r d \Delta P B)$ did not cause expansion of odd-numbered en stripes, as observed with ectopic prd. Instead, the odd-numbered en stripes were completely or partially deleted; the even-numbered en stripes were unaffected.

Formally, this result suggests that the $\operatorname{Prd} \Delta \mathrm{PB}$ protein acts as a repressor of en. However, it is not a general repressor of en, as only the odd-numbered stripes are deleted. These data suggest that the presence of $\operatorname{Prd} \Delta \mathrm{PB}$ is able to poison the specification of only the odd-numbered stripes. As discussed earlier, the specification of odd-numbered stripes is thought to depend on the combination of prd and eve function. Indeed, the poisoning of odd-numbered stripes by $\operatorname{Prd} \Delta \mathrm{PB}$ mimics the phenotypes of loss-of-function mutants in prd and eve in which oddnumbered en stripes are deleted (Harding et al. 1986; Macdonald et al. 1986; DiNardo and O'Farrell 1987) (eve mutants also lack even-numbered en stripes, possibly due to indirect effects on $\mathrm{ftz}$ expression; Frasch et al. 1988). This dominant negative effect of $\operatorname{Prd} \Delta \mathrm{PB}$ occurs despite the presence of wild-type prd and eve in hsprd $\triangle P B$ embryos.

To explain this dominant negative effect, we propose that $\operatorname{Prd} \Delta \mathrm{PB}$ competes for ligands with wild-type Prd, blocking its normal function. However, as Prd $\Delta$ PB lacks part of the Prd protein, it may not function successfully and, instead, interferes with and poisons the function of the resident wild-type Prd protein. The Prd $\triangle \mathrm{PB}$ could poison the binding of Prd either to itself or to other proteins or it may interfere with Prd binding to DNA. Consistent with this interpretation of the dominant negative phenotype, expression of the endogenous prd and eve transcripts is not detectably altered in heat-treated $h s-$ prd $\triangle P B$ embryos (not shown). Our observation that deletion of the paired box converts prd into a dominant negative regulator provides the first indication that the paired box is important for normal prd function in the Drosophila embryo. However, it is possible that the paired-box deletion might have caused conformational changes in other parts of the Prd protein that are responsible for the change in prd function. 
Like the homeo box, the paired box has been postulated to encode a DNA-binding activity (Burri et al. 1989; Treisman et al. 1991). Perhaps the function of the normal Prd protein requires DNA (or protein) targeting by both the homeo domain and paired-box domain of the protein, and the ectopic Prd $\triangle P B$ protein does not function successfully because it lacks one of these two binding activities.

Interestingly, ectopic expression of Prd $\triangle \mathrm{PB}$ resulted in an altered cuticle pattern similar to that observed in gooseberry ${ }^{-}$embryos (Nüsslein-Volhard and Wieschaus 1980). It seems unlikely that the gooseberry ${ }^{-}$phenocopy is an indirect consequence of the poisoning of endogenous prd, as the striped expression of gooseberry RNA (BSH9; Baumgartner et al. 1987) is not detectably diminished or altered in heat-treated hs-prd $\triangle P B$ embryos (not shown). However, as the gooseberry gene contains a paired box and a homeo box encoding very similar protein sequences to those in the homologous domains of the prd gene (Bopp et al. 1986), it is possible that in addition to poisoning endogenous prd, the ectopic $\operatorname{Prd} \triangle \mathrm{PB}$ may also poison the function of endogenous gooseberry by binding its ligands, thereby explaining the gooseberry ${ }^{-}$phenocopy.

\section{A Ftz/Prd chimera also deletes odd-numbered en stripes}

The effects of ectopic $f t z$ and ectopic prd are distinguishable in that ectopic $f t z$ broadens even-numbered en stripes, whereas ectopic prd broadens odd-numbered en stripes (see Fig. 1). To determine whether these different ectopic functions depend on regions of the protein inside or outside the homeo domain, we constructed a chimeric gene coding for a Ftz protein with residues $3-61$ of the Ftz homeo domain substituted with the equivalent residues of the $\mathrm{prd}$ gene homeo domain (Ftz/PrdHD/Ftz). Previous homeo domain swapping experiments involving homeotic genes (Kuziora and McGinnis 1989, 1991; Gibson et al. 1990; Mann and Hogness 1990; for review, see Hayashi and Scott 1990) have suggested that the DNA (or possibly protein) targeting of the chimeras depends on regions within the homeo domain, whereas the quality of gene regulation by the chimera (whether it is positive or negative) depends on regions outside the homeo domain.

Ectopic expression of the $\mathrm{Ftz} / \mathrm{PrdHD} / \mathrm{Ftz}$ protein caused partial or complete deletion of odd-numbered en stripes, similar to that observed with ectopic Prd $\Delta$ PB. Using parallel reasoning to that above, we propose that the Ftz/PrdHD/Ftz chimera, like Prd $\Delta \mathrm{PB}$, binds to ligands of the Prd protein and thereby poisons the function of the endogenous prd gene. Presumably, the chimera would bind to targets of Prd because it has a Prd homeo domain, but it does not function successfully like ectopic Prd because it lacks the rest of the Prd protein. Hence, this result is consistent with the proposal that regions within the homeo domain are important in determining the specification of targeting of these proteins. This interpretation is supported by the observation that ectopic Ftz, unlike Ftz/PrdHD/Ftz, does not cause deletion of odd-numbered en stripes, presumably because ectopic Ftz does not bind targets of Prd.

Implicit in this interpretation is the idea that within the chimera, the Ftz sequences flanking the Prd homeo domain do not substitute for the absent Prd-flanking sequences. Perhaps, Ftz/PrdHD/Ftz lacks Prd domains necessary for combinatorial mechanisms involving proteinprotein or protein-DNA interactions, an idea consistent with our hs-prd $\triangle P B$ result. Our observation of poisoning as a consequence of putative Prd-like targeting may reflect the complexity of combinatorial regulation of segmentation genes, structural components of which are not simply additive or interchangeable. This is in contrast to the results of previous homeo domain swapping experiments with homeotic genes in which poisoning has not been observed (Kuziora and McGinnis 1989, 1991; Gibson et al. 1990; Mann and Hogness 1990). Instead, the combined heterologous structural domains have been additive in their net functions, with the targeting specificity of the chimera appearing to be that of the homeo domain and the regulation quality (whether positive or negative) reflecting normal regulation of the gene contributing the flanking sequences (Kuziora and McGinnis 1989, 1991).

Our chimera result extends the $h s-p r d \triangle P B$ result to suggest that the Prd homeo domain is sufficient to mediate the observed poisoning effect. Because the homeo domain is thought to have DNA-binding activity, the poisoning could be due to binding to normal DNA targets of Prd. However, it is also possible that the poisoning is a consequence of protein-protein interactions mediated by the Prd homeo domain. Indeed, there is a precedent for this possiblity: The homeo domain of Oct-1 (a POU-domain protein) has been shown to bind the herpes simplex virus trans-activator, VP16, through residues in the first helix and turn in the helix-turn-helix motif of the Oct-1 homeo domain (Stern et al. 1989). A second case of protein-protein interactions between homeo domain proteins has been documented for two other POUdomain proteins, I-POU and CFla, although in this case the interaction occurs through the POU domains of both proteins (located upstream of their homeo domains) (Treacy et al. 1991). Interestingly, when these two proteins form a heterodimer, the CFla protein loses its ability to bind DNA and no longer activates the Drosophila dopa-decarboxylase gene. It is an intriguing possibility that this inactivation of one homeo domain protein by another might be analogous to the poisoning effects of $\operatorname{Prd} \Delta \mathrm{PB}$ and $\mathrm{Ftz} / \mathrm{PrdHD} / \mathrm{Ftz}$.

\section{Ftz/PrdHD/Ftz has ectopic Ftz function}

In addition to deleting the odd-numbered en stripes, ectopic expression of $\mathrm{Ftz} / \mathrm{PrdHD} / \mathrm{Ftz}$ also caused broadening of even-numbered en stripes, as observed when unaltered $\mathrm{Ftz}$ protein is ectopically expressed (Ish-Horowicz et al. 1989). This result is rather unexpected because it suggests that the Ftz/PrdHD/Ftz chimera can 
bind to normal DNA (or protein) targets of Ftz protein, despite having a Prd homeo domain and despite apparently being able to bind targets of Prd (see above). Although it is formally possible that the chimera binds to targets of the Prd protein, but still manages to provide an ectopic effect such as that of $f t z$, this seems unlikely, especially given that the chimera also autoregulates the endogenous $f t z$ gene and causes an altered cuticle pattern as observed with ectopic $f t z$. These results are explained most easily assuming that the chimera binds to targets of the unaltered Ftz protein.

It is conceivable that this ectopic $f t z$-like function does not depend on targeting by the chimera's Prd homeo domain but, instead, depends on protein or DNA interactions by Ftz regions outside the homeo domain. However, it seems more likely that the ftz-like effect is mediated by the chimera's Prd homeo domain. Assuming this second interpretation, and given that it is unlikely that the Prd homeo domain in its normal context / the Prd protein) binds to targets of the Ftz protein, the proposal that the Ftz/PrdHD/Ftz chimera can bind these (Ftz) targets suggests that regions outside the homeo domain are important in conferring this targeting property to the chimera's homeo domain. Either the presence of Ftz sequences outside the homeo domain or the absence of Prd flanking sequences might be responsible for this effect. The possible importance in DNA targeting of regions flanking the homeo domain has been suggested previously by structural studies of the homeo domains of en (Kissinger et al. 1990) and Antennapedia (Otting et al. 1990), which indicate that residues very near the aminoterminal end within the homeo domain make specific contacts with target DNA. This suggested that regions of the protein outside the homeo domain might be important in positioning these residues for correct DNA binding. It is interesting to note that within subfamilies of homeo domain proteins, there is often significant conservation of regions immediately upstream or downstream of the homeo box [e.g., engrailed/invected/Coleman et al. 1987), paired/gooseberry-proximal/gooseberry-distal (Bopp et al. 1986), Deformed-like genes (see Scott et al. 1989|]. Because they are conserved, these regions would be expected to have some functional importance. Furthermore, we note that our Ftz/PrdHD/Ftz chimera was constructed with substitution of only residues 3-61 of the homeo domain, and this chimera apparently retained targeting of $\mathrm{Ftz}$; whereas previous homeo box swaps by others have included the homeo domain plus several residues upstream or downstream of the homeo domain, and these chimeras apparently did not retain targeting specificity normally associated with the homeo domain that was replaced (Kuziora and McGinnis 1989, 1991). However, the significance of this correlation remains to be tested.

In summary, the dual effects of the Ftz/PrdHD/Ftz protein on en expression (deletion of odd-numbered stripes and expansion of even-numbered stripes) suggest that the chimeric protein may be able to bind to targets of both the Ftz and Prd proteins. This indicates that sequences both inside and outside of the homeo domain may be important in determining the specificity of targeting of these homeo domain proteins.

\section{Materials and methods}

Construction of hs-prd embryos

A HindIII-EcoRI fragment of prd cDNA (c7340.6; Frigerio et al. 1986) was ligated, with KpnI linkers, into the KpnI site of the vector $p H T 4$ (Schneuwly et al. 1987). This vector contains both $h s p 70$ promoter and polyadenylation sequences, allowing for heat-inducible expression of the inserted gene (Fig. 3A). The pHT4/prd construct (hs-prd) was coinjected (Rubin and Spradling 1982) with the disabled P-element vector $p \pi 25.7 w c$ (Laski et al. 1986) into rosy ${ }^{506}$ embryos. Three independent rosy ${ }^{+}$ transformant lines were obtained, none of which were homozygous fertile. However, mobilization of one of these hs-prd insertions to new chromosomal locations with $\Delta 2-3$ (Cooley et al. 1988) resulted in several homozygous fertile lines. For our studies we used two transformant lines, one homozygous fertile, and the other a balanced homozygous infertile line; equivalent results were obtained with both lines.

\section{Construction of hs-ftz/prdHD/ftz and hs-prd $\Delta \mathrm{PB}$ embryos}

To replace the $f t z$ homeo box with that from the prd gene, a prd homeo box fragment was generated by polymerase chain reaction (PCR), containing a Hinfl site at its $5^{\prime}$ end and a blunt $3^{\prime}$ end (Fig. 3C). The prd homeo box fragment was blunt-end ligated to a ftz 3'-arm fragment, which was also generated by PCR with $f t z H R 1.9$ as template [a $f t z$ genomic clone that includes a substitution of $f t z$ cDNA removing the intron (Struhl 1985), and an introduced HindIII site $\sim 90$ bp upstream of the translation start site (G. Winslow, pers. comm.)]. The ligation product of the two PCR fragments was gel-isolated and ligated to the $f t z 5^{\prime}$ arm (HindIII-HinfI) fragment of $f t z$ HR1.9. The complete chimeric gene was subcloned into pBluescript and the PCR-generated regions were sequenced to ensure complete fidelity of the Taq polymerase.

Deletion of the paired box was also accomplished by using PCR, making use of an EagI site at the 3' end of the paired box (Fig. 3B). PCR was used to generate a fragment extending from the HindIII site of prd to the $5^{\prime}$ end of the paired box, to which an EagI site was incorporated. This PCR fragment, which lacked the paired box, was used to replace, by ligation, an equivalent HindIII-EagI fragment of prd cDNA in pGEM-2. The PCR-generated region was then sequenced.

The HindIII-EcoRI fragment of both the $f t z / p r d H D / f t z$ chimera and the paired-box deletion were subcloned into the polylinker of the vector $p H S B$ ( Malicki et al. 1990), which is flanked on one side by the $h s p 70$ promoter and on the other side by polyadenylation signals from the Adh gene. NotI fragments from these subclones, containing the modified gene and regulatory sequences on either side, were subcloned into the NotI site of the P-element vector $p W 8$ (Klemenz et al. 1987) that contains the white ${ }^{+}$gene. These constructs were injected with helper plasmid $(p \pi 25.7 w c)$ into $D f(1) w^{67 c 23} y$ embryos, and white ${ }^{+}$ transformants selected. Seven transformant lines were obtained for the $h s-f t z / p r d H D / f t z$ chimera, and seven lines for hsprd $\triangle P B$. Two homozygous fertile lines for each construct were analyzed for cuticle and expression studies, and equivalent results were obtained with the different insertion sites for each construct.

\section{Identification of mutant embryos}

To identify embryos homozygous for eve $e^{1.27}$, we used a mutant 
stock containing a balancer chromosome $(\mathrm{CyO})$ onto which we had jumped a lacZ gene driven by a hunchback promoter (Driever et al. 1989). Embryos containing this balancer have lac $Z$ expression throughout the anterior half of the embryo, a pattern easily distinguished from that of en. In situ hybridization was performed with en and lacZ probes simultaneously, and homozygous eve $e^{1.27}$ embryos were distinguished by their lack of the hunchback-lacZ pattern.

\section{Heat treatment of embryos}

Embryos collected ( $30 \mathrm{~min}$ ) on agar plates (seeded with glacial acetic acid and yeast) were incubated at $25^{\circ} \mathrm{C}$ until $10-20 \mathrm{~min}$ before heat treatment. Embryos were rinsed from the agar plates with water, rinsed with $0.7 \% \mathrm{NaCl}$ and $0.04 \%$ Triton $\mathrm{X}-100$, dechorionated in $50 \%$ Clorox for $2.5 \mathrm{~min}$, and placed in a watch glass with $\mathrm{NaCl}-\mathrm{Triton}$ solution at $25^{\circ} \mathrm{C}$. Heat treatment was performed by submerging the embryos in $\mathrm{NaCl}$-Triton solution at $37^{\circ} \mathrm{C}$ with either $(1)$ one pulse of 5,10 , or $20 \mathrm{~min}$ at $170-200$ min AED, or (2) two 5-min pulses, the first at 140-170 min AED and the second $30 \mathrm{~min}$ later. After heat treatment, embryos were returned immediately to $\mathrm{NaCl}-\mathrm{Triton}$ solution at $25^{\circ} \mathrm{C}$. Embryos were processed either for cuticle preparations or in situ hybridization (see below). For larval cuticle analysis, embryos were incubated for 30-40 hr after heat treatment, fixed for $1 \mathrm{hr}$ at $60^{\circ} \mathrm{C}$ in glycerol-glacial acetic acid $(1: 4)$, and mounted in Hoyer's medium (Wieschaus and Nüsslein-Volhard 1986).

\section{In situ hybridization}

Our in situ hybridization method to detect mRNA was based on methods of Tautze and Pfeifle (1989) with modifications according to S. DiNardo, B. Edgar, and C. Oh (pers. comm.). After dechorionation, heat shock treatment, and incubation at $25^{\circ} \mathrm{C}$ (see above), embryos were fixed for $20 \mathrm{~min}$ in $4 \mathrm{ml}$ of heptane, $4 \mathrm{ml}$ of $1.5 \times$ PEM with $10 \%$ formaldehyde $[1 \times \mathrm{PEM}$ is $100 \mathrm{mM}$ PIPES (pH 6.8), 2 mM EGTA, $1 \mathrm{~mm} \mathrm{MgCl}_{2}$ ). Devitellinization was performed according to Mitchison and Sedat (1983) by removing the aqueous layer, adding $6 \mathrm{ml}$ of MetOH, and shaking vigorously for $5 \mathrm{~min}$. After devitellization, embryos were rinsed three times in MetOH and three times in 95\% EtOH, $5 \mathrm{~min}$ each. The embryos were stored up to 6 months in $\mathrm{EtOH}$ at $-20^{\circ} \mathrm{C}$

Fixed embryos stored in EtOH were rinsed for $5 \mathrm{~min}$ in $\mathrm{MetOH}$ and for $5 \mathrm{~min}$ in $\mathrm{MetOH}-\mathrm{PBT}$ with $4 \%$ formaldehyde (PBTf) $(1: 1)$ and fixed for $20 \mathrm{~min}$ in PBTf [PBT is PBS (130 mM $\mathrm{NaCl}, 7 \mathrm{mM} \mathrm{Na}_{2} \mathrm{HPO}_{4}, 3 \mathrm{mM} \mathrm{NaH} \mathrm{PO}_{4} /$ with $0.1 \%$ Tween 20 ]. Rinses and fixes were performed in 5-ml culture tubes with 4.5 $\mathrm{ml}$ of solution. After fixing, the embryos were rinsed three times for $5 \mathrm{~min}$ in PBT. The embryos were then digested with $50 \mathrm{mg} / \mathrm{ml}$ of proteinase $\mathrm{K}$ (Boehringer) for $6 \mathrm{~min}$. Digestion was stopped by rinsing twice for $30 \mathrm{sec}$ in PBT with $2 \mathrm{mg} / \mathrm{ml}$ of glycine. The embryos were then rinsed twice for $5 \mathrm{~min}$ in PBT and postfixed for $20 \mathrm{~min}$ in PBTf. The fixative was removed with five rinses, 5 min each, in PBT. The embryos were moved to $1.5-\mathrm{ml}$ silanized Eppendorf tubes for hybridization. After 10 min at $48^{\circ} \mathrm{C}$ in $100 \mu \mathrm{l}$ of PBT-hybridization solution (HS) (1:1), followed by $100 \mu \mathrm{l}$ of $\mathrm{HS}$, the embryos were prehybridized for 1 $\mathrm{hr}$ in $\mathrm{HS}$ (HS is $50 \%$ deionized formamide, $5 \times \mathrm{SSC}, 100 \mu \mathrm{g} / \mathrm{ml}$ of sonicated boiled salmon sperm, $100 \mu \mathrm{g} / \mathrm{ml}$ of tRNA, $50 \mu \mathrm{g} / \mathrm{ml}$ of heparin, $0.1 \%$ Tween 20 , stored at $-70^{\circ} \mathrm{C}$ for $\leqslant 60$ days). The embryos were hybridized overnight at $48^{\circ} \mathrm{C}$ in $50 \mu \mathrm{l}$ of HS with 5-10 ng of the probes.

Probes were prepared from isolated fragments of $e n, f t z, p r d$, $e v e$ and BSH9 cDNAs. DNA $(50-100 \mathrm{ng})$ and $0.1-\mu \mathrm{g}$ random primers [pd(N)6, Pharmacia] (14 $\mu$ l total volume) was denatured at $95^{\circ} \mathrm{C}$ for $5 \mathrm{~min}$ and quick-chilled on ice. Two microliters of
$10 \times$ Vogel buffer [1 M PIPES (pH 6.8), $50 \mathrm{~mm} \mathrm{MgCl}_{2}, 100 \mathrm{~mm}$ 2-mercaptoethanol], $2.0 \mu \mathrm{l}$ of deoxynucleotide mix containing digoxygenin-dUTP (Genius kit, Boehringer), and 2 units of Klenow were added. This incorporation reaction was incubated overnight at $14^{\circ} \mathrm{C}$ and then for $4 \mathrm{hr}$ at room temperature after adding 2 units more of Klenow. The reaction was stopped by adding $0.5 \mathrm{M}$ EDTA to $50 \mathrm{~mm}$ and incubating at $65^{\circ} \mathrm{C}$ for $10 \mathrm{~min}$. The probe was precipitated at $-70^{\circ} \mathrm{C}$ after the addition of $80 \mu \mathrm{l}$ of $\mathrm{H}_{2} \mathrm{O}, 50 \mu \mathrm{g}$ of tRNA, $3 \mathrm{~m} \mathrm{NaOAc}$ to $300 \mathrm{~mm}$, and $300 \mu \mathrm{l}$ of EtOH. The probe was resuspended in $50 \mu \mathrm{l}$ of HS and applied to the embryos after being diluted further in HS $(1: 10)$, denatured for $3 \mathrm{~min}$ at $95^{\circ} \mathrm{C}$, and quick-chilled on ice.

After probe hybridization to embryos overnight, excess probe was removed by rinsing at $48^{\circ} \mathrm{C}$ in $500 \mu \mathrm{l}$ of $\mathrm{HS}, 500 \mu \mathrm{l}$ of HS-PBT $(1: 1)$, and rinsing five times in $1 \mathrm{ml}$ of PBT (the last three rinses were at room temperature). The embryos were then incubated for $\mathrm{l} \mathrm{hr}$ at room temperature in anti-digoxygenin alkaline phosphatase-conjugated antibodies (Genius kit, Boehringer $)$ in PBT $(1: 2000)$. The excess antibodies were removed with four washes, 20 min each, in PBT. The embryos were rinsed three times for $5 \mathrm{~min}$ in X-phosphate buffer [ $100 \mathrm{~mm}$ Tris (pH 9.5), $100 \mathrm{~mm} \mathrm{NaCl}, 50 \mathrm{~mm} \mathrm{MgCl}_{2}, 1 \mathrm{~mm}$ levamisol, and $0.1 \%$ Tween 20 l. To the third rinse $4.5 \mu \mathrm{l}$ of nitroblue tetrazolium (NBT) and $3.5 \mu$ l of X-phosphate (Genius kit, Boehringer) were added for color reaction (performed in the dark). The reaction was stopped after $1-40 \mathrm{hr}$ by rinsing three times for $20 \mathrm{~min}$ in PBT. The embryos were left at $4^{\circ} \mathrm{C}$ in PBT for 2-10 days before staining with DAPI $(0.5 \mu \mathrm{g} / \mathrm{ml}$; Sigma) and mounting in Aqua-Poly/Mount (Polysciences).

\section{Acknowledgments}

We are grateful to Marcus Noll for a prd cDNA, Greg Gibson and Walter Gehring for the pHT4 vector, Brad Jones and Bill McGinnis for the $p H S B I$ vector, and Wolfgang Driever and Christiane Nüsslein-Volhard for fly stocks. We also thank Jim Donady, Laura Grabel, Tom Kornberg, and two of the reviewers for useful comments on the manuscript. This work was supported by a grant from the National Institutes of Health (GM 42752) to M.W.

The publication costs of this article were defrayed in part by payment of page charges. This article must therefore be hereby marked "advertisement" in accordance with 18 USC section 1734 solely to indicate this fact.

\section{References}

Akam, M. 1987. The molecular basis for metameric patterning in the Drosophila embryo. Development 101: 1-22.

Balling, R., U. Deutsch, and P. Gruss. 1988. Undulated, a mutation affecting the development of the mouse skeleton, has a point mutation in the paired box of Pax-1. Cell 55: 531535.

Baumgartner, S., D. Bopp, M. Burri, and M. Noll. 1987. Structure of two genes at the goosberry locus related to the paired gene and their spatial expression during Drosophila embryogenesis. Genes \& Dev. 1: 1247-1267.

Bopp, D., M. Burri, S. Baumgartner, G. Frigerio, and M. Noll. 1986. Conservation of a large protein domain in the segmentation gene paired and in functionally related genes in Drosophila. Cell 47: 1033-1049.

Burri, M., Y. Tromvoukis, D. Bopp, G. Frigerio, and M. Noll. 1989. Conservation of the paired domain in metazoans and its structure in three isolated human genes. EMBO $J$. 8: 1183-1190. 
Carroll, S.B. 1990. Zebra patterns in fly embryos: Activation of stripes or repression of interstripes? Cell 60: 9-16.

Coleman, K.G., S.J. Poole, M.P. Weir, W.C. Soeller, and T. Kornberg. 1987. The invected gene of Drosophila: Sequence analysis and expression studies reveal a close kinship to the engrailed gene. Genes \& Dev. 1: 19-28.

Cooley, L., R. Kelley, and A. Spradling. 1988. Insertional mutations of the Drosophila genome with single P elements. Science 239: 1121-1128.

DiNardo, S. and P.H. O'Farrell. 1987. Establishment and refinement of segmental pattern in the Drosophila embryo: Spatial control of engrailed expression by pair-rule genes. Genes \& Dev. 1: 1212-1225.

DiNardo, S., J.M. Kuner, J. Theis, and P.H. O'Farrell. 1985. Development of embryonic pattern in $D$. melanogaster as revealed by accumulation of the nuclear engrailed protein. Cell 43: 56-69.

Driever, W., G. Thoma, and C. Nüsslein-Volhard. 1989. Determination of spatial domains of zygotic gene expression in the Drosophila embryo by the affinity of binding sites for the bicoid morphogen. Nature 340: 363-367.

Frasch, M., R. Warrior, J. Tugwood, and M. Levine. 1988. Molecular analysis of even-skipped mutants in Drosophila development. Genes \&) Dev. 2: 1824-1838.

Frigerio, G., M. Burri, D. Bopp, S. Baumgartner, and M. Noll. 1986. Structure of the segmentation gene paired and the Drosophila PRD gene set as part of a gene network. Cell 47: 735-746.

Gergen, J.P., D. Coulter, and E. Wieschaus. 1986. Segmental pattern and blastoderm cell identities. In Gametogenesis and the early embryo (ed. J.G. Gall), pp. 195-220. Alan R. Liss, New York.

Gibson, G., A. Schier, P. LeMotte, and W.H.J. Gehring. 1990. The specificities of Sex combs reduced and Antennapedia are defined by a distinct portion of each protein which includes the homeodomain. Cell 62: 1087-1103.

Harding, K., C. Rushlow, H.J. Doyle, T. Hoey, and M. Levine. 1986. Cross-regulatory interactions among pair-rule genes in Drosophila. Science 233: 953-959.

Hayashi, S. and M.P. Scott. 1990. What determines the specificity of action of Drosophila homeodomain proteins? Cell 63: $883-894$.

Hoey, T. and M. Levine. 1988. Divergent homeo box proteins recognize similar DNA sequences in Drosophila. Nature 332: 858-861.

Howard, K. and P. Ingham. 1986. Regulatory interactions between the segmentation genes fushi tarazu, hairy, and engrailed in the Drosophila blastoderm. Cell 44: 949-957.

Ingham, P.W. 1988. The molecular genetics of embryonic pattern formation in Drosophila. Nature 335: 25-34.

Ingham, P.W., N.E. Baker, and A. Martinez-Arias. 1988. Regulation of segment polarity genes in the Drosophila blastoderm by fushi tarazu and even-skipped. Nature 331: 73-75.

Ish-Horowicz, D., S.M. Pinchin, P.W. Ingham, and H.G. Gyurkovics. 1989. Autocatalytic $f t z$ activation and metameric instability induced by ectopic $f t z$ expression. Cell 57: 223-232.

Karr, T.L., M.P. Weir, Z. Ali, and T. Kornberg. 1989. Patterns of engrailed protein in early Drosophila embryos. Development 105: 605-612.

Kilchherr, K., S. Baumgartner, D. Bopp, E. Frei, and M. Noll. 1986. Isolation of the paired gene of Drosophila and its spatial expression during early embryogenesis. Nature 321: 493-499.

Kissinger, C.R., B. Liu, E. Martin-Blanco, T.B. Kornberg, and C.O. Pabo. 1990. Crystal structure of an engrailed homeodomain-DNA complex at $2.8 \AA ̊$ resolution: A framework for understanding homeodomain-DNA interactions. Cell 63: $579-590$.

Klemenz, R., U. Weber, and W.J. Gehring. 1987. The white gene as a marker for a new P-element vector for gene transfer in Drosophila. Nucleic Acids Res. 15: 3947-3959.

Kuziora, M.A. and W. McGinnis. 1989. A homeodomain substitution changes the regulatory specificity of the Deformed protein in Drosophila. Cell 59: 563-571.

. 1991. Altering the regulatory targets of the Deformed protein in Drosophila embryos by substituting the Abdominal-B homeodomain. Mech. Dev. 33: 83-94.

Laski, F.A., D.C. Rio, and G.M. Rubin. 1986. Tissue specificity of Drosophila P element transposition is regulated at the level of mRNA splicing. Cell 44: 7-19.

Laughon, A. and M.P. Scott. 1984. Sequence of a Drosophila segmentation gene: Protein structure homology with DNAbinding proteins. Nature 310: 21-35.

Lawrence, P.A., P. Johnson, P. Macdonald, and G. Struhl. 1987. Borders of parasegments in Drosophila embryos are delimited by the fushi tarazu and even-skipped genes. Nature 328: 440-442.

Macdonald, P.W., P. Ingham, and G. Struhl. 1986. Isolation, structure, and expression of even-skipped: A second pairrule gene of Drosophila containing a homeobox. Cell 47: 721-734.

Malicki, J., K. Schughart, and W. McGinnis. 1990. Mouse Hox 2.2 specifies thoracic segmental identity in Drosophila embryos and larvae. Cell 63: 961-967.

Mann, R.S. and D.S. Hogness. 1990. Functional dissection of Ultrabithorax proteins in D. melanogaster. Cell 60: $597-$ 610.

McGinnis , W., M.S. Levine, E. Hafen, A. Kuriowa, and W.J. Gehring. 1984. A conserved DNA sequence in homeotic genes of the Drosophila Antennapedia and bithorax complexes. Nature 308: 428-433.

Mitchison, T.J. and J. Sedat. 1983. Localization of antigenic determinants in whole Drosophila embryos. Dev. Biol. 99: 261-264.

Nüsslein-Volhard C. and E. Wieschaus. 1980. Mutations affecting segment number and polarity in Drosophila. Nature 287: 795-801.

Otting, G., Y.-q. Qian, M. Muller, M. Affolter, W. Gehring, and K. Wuthrich. 1990. Protein-DNA contacts in the structure of a homeodomain-DNA complex determined by nuclear magnetic resonance spectroscopy in solution. EMBO J. 9: 30853092.

Rubin, G. M. and A.C. Spradling. 1982. Genetic transformation of Drosophila with transposable element vectors. Science 218: 348-353.

Schneuwly, S. R., R. Klemenz, and W.J. Gehring. 1987. Redesigning the body plan of Drosophila by ectopic expression of the homeotic gene Antennapedia. Nature 325: 816-818.

Scott, M.P., J.W. Tamkun, and G.W. Hartzell. 1989. The structure and function of the homeodomain. Biochim. Biophys. Acta 989: 25-48.

Stern, S., M. Tanaka, and W. Herr. 1989. The Oct-1 homeodomain directs formation of a multiprotein-DNA complex with the HSV transactivator VP16. Nature 341: 624-630.

Struhl, G. 1985. Near reciprocal phenotypes caused by inactivation or indiscriminate expression of the Drosophila segmentation gene $f t z$. Nature 318: 677-680.

Tautze, D. and C. Pfeifle. 1989. A non-radioactive in situ hybridization method for the localization of specific RNAs in Drosophila embryos reveals translational control of the segmentation gene hunchback. Chromosoma 98: 81-85.

Treacy, M.N., X. He, and M.G. Rosenfeld. 1991. I-POU: A POU- 
domain protein that inhibits neuron-specific gene activation. Nature 350: 577-584.

Treisman, J., E. Harris, and C. Desplan. 1991. The paired box encodes a second DNA-binding domain in the Paired homeo domain protein. Genes \& Dev. 5: 594-604.

Treisman, J., P. Gonczy, M. Vashishtha, E. Harris, and C. Desplan. 1989. A single amino acid change can determine the DNA binding specificity of homeodomain proteins. Cell 59: 553-562.

Weir, M. P. and T. Kornberg. 1985. Patterns of engrailed and fushi tarazu transcripts reveal novel intermediate stages in Drosophila segmentation. Nature 318: 433-439.

Weir, M.P., B.A. Edgar, T. Kornberg, and G. Schubiger. 1988. Spatial regulation of engrailed expression in the Drosophila embryo. Genes \& Dev. 2: 1194-1203.

Wieschaus, E. and C. Nüsslein-Volhard. 1986. Looking at embryos. In Drosophila: A practical approach (ed. D.B. Roberts), pp. 199-227. IRL Press, Oxford. 


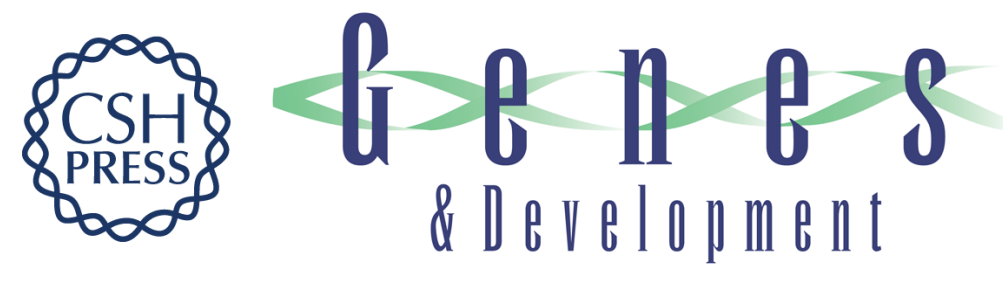

\section{Functional dissection of the paired segmentation gene in Drosophila embryos.}

D Morrissey, D Askew, L Raj, et al.

Genes Dev. 1991, 5:

Access the most recent version at doi:10.1101/gad.5.9.1684

References This article cites 48 articles, 10 of which can be accessed free at: http://genesdev.cshlp.org/content/5/9/1684.full.htmI\#ref-list-1

License

Email Alerting

Receive free email alerts when new articles cite this article - sign up in the box at the top Service right corner of the article or click here.

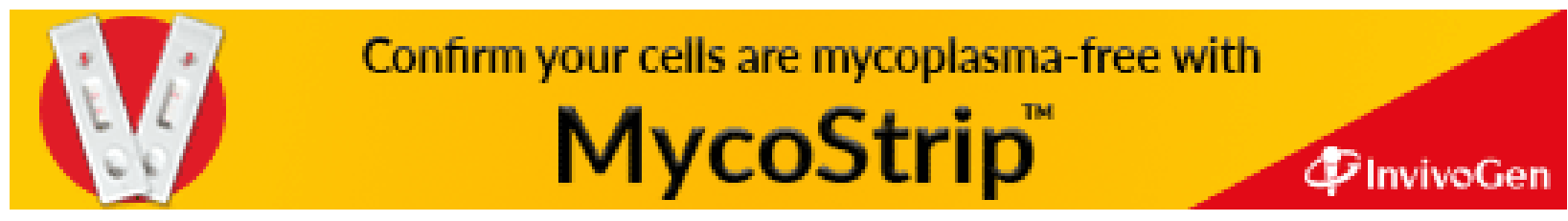

